\title{
Gênero e sexualidade: diálogos e inquietações com/da/na educação básica
}

\author{
Género y sexualidad: diálogos e inquietudes con / da / en la educación \\ básica
}

\author{
Gender and sexuality: dialogues and concerns with / in / in basic \\ education
}

\author{
Sara de Souza Fernandes Epitácio ${ }^{1}$ \\ Nola Patricia Gamalho² \\ Gladis Kunz Rosa ${ }^{3}$ \\ Ewerton da Silva Ferreira ${ }^{4}$
}

\begin{abstract}
Resumo
O presente artigo tem por objetivo problematizar as discussões sobre currículo, gênero e sexualidades. Parte-se das atividades do projeto de extensão: "Construções e desconstruções do gênero e sexualidade no currículo: tecendo perspectivas para uma educação multicultural", realizado pela Universidade Federal do Pampa (UNIPAMPA), campus São Borja, juntamente com as escolas da rede de Educação Básica do município. O desenvolvimento dessas atividades, ocorridas no formato de palestras, rodas de debate e atividades práticas, foram fundamentais para propiciar espaços de diálogo. No município em questão predominam historicamente latifúndios voltados para a pecuária e monoculturas, o que implicou em uma estrutura social fortemente assentada no patriarcado e, desta forma, com ramificações nas organizações sociais, políticas, imaginários e representacionais. Portanto, o objetivo de dialogar e desconstruir imaginários de gênero e sexualidade, além de ser um desafio, é uma necessidade emergente. Assim, o texto discorre sobre o contexto espacial e histórico do município; desenvolve uma discussão conceitual sobre gênero, sexualidade e currículo. Por fim, a partir da análise das atividades desenvolvidas, são tecidas reflexões sobre a identidade docente e práticas pedagógicas. Gênero, sexualidade e educação são temas intrincados e em disputa. Assim, as reflexões aqui expostas inseremse na luta política e social para a constituição de sociedades que aprendam com as diferenças e diversidades.
\end{abstract}

Palavras-Chave: Educação Básica; Gênero; Patriarcado; Sexualidade; São Borja/RS.

Resumen
El presente
género y y sexualículo tiene por objetivo problematizar las discusiones sobre currículo,

\footnotetext{
${ }^{1}$ Professora Doutora do Curso de Ciências Humanas - Ciência Política da Universidade Federal do Pampa UNIPAMPA, Campos São Borja. E-mail: saraepitacio@unipampa.edu.br

${ }^{2}$ Professora do curso de Ciências Humanas- Licenciatura da Universidade Federal do Pampa e coordenadora do projeto de Extensão: Construções e desconstruções do gênero e sexualidade no currículo: tecendo perspectivas para uma educação multicultural. E-mail: nolagamalho@unipampa.edu.br

${ }^{3}$ Acadêmica do curso de Ciências Humanas - Licenciatura da Universidade Federal do Pampa - UNIPAMPA campus São Borja - RS. Bolsista do Projeto de Extensão: Construção e Desconstrução do gênero e sexualidade no currículo: tecendo perspectivas para uma educação multicultural. Membro do GEEP - Grupo de Pesquisa em Gênero, Ética, Educação e Política. E-mail: gladiswolff@ gmail.com

${ }^{4}$ Acadêmico do curso de Ciências Humanas - Licenciatura da Universidade Federal do Pampa - UNIPAMPA campus São Borja. Membro do GEEP - Grupo de Pesquisa em Gênero, Ética, Educação e Política. E-mail: ewertonferreira266@gmail.com
} 
"Construcciones y desconstrucciones del género y sexualidad en el currículo: tejiendo perspectivas para una educación multicultural", realizado por la Universidade Federal do Pampa (UNIPAMPA - São Borja), en colaboración con escuelas de Educación Básica del municipio. El desarrollo de las actividades ocurridas en forma de palestras, debates y actividades prácticas, fueron fundamentales para propiciar espacios de diálogo. En el municipio en cuestión predominan históricamente latifundios destinados para la pecuaria y los monocultivos, lo que implicó en una estructura social fuertemente asentada en el patriarcado y, así, con ramificaciones en las organizaciones sociales, políticas, imaginarios y representaciones. Por lo tanto, el objetivo de dialogar y desconstruir imaginarios de género y sexualidad, además de ser un desafio, es una necesidad emergente. Así, el texto examina el contexto espacial e histórico del municipio; desarrolla una discusión conceptual acerca del género, sexualidad y currículo. Finalmente, desde el análisis de las actividades desarrolladas, son presentadas reflexiones sobre la identidad docente y las prácticas pedagógicas. Género, sexualidad y educación son asuntos complejos y en constante disputa. Así, las reflexiones aquí presentadas si introducen en la lucha política y social por sociedades que aprendan con las diferencias y diversidades.

Palavras clave: Educación Básica; Género; Patriarcado; Sexualidad; São Borja/RS.

\begin{abstract}
The present paper aims to problematize discussions about curriculum, gender and sexualities. Based on the activities of the extension project "Constructions and deconstructions of gender and sexuality in the curriculum: weaving perspectives for a multicultural education", carried out by the Federal University of Pampa (UNIPAMPA-São Borja), in partnership with schools of Basic Education municipality. The development of these activities, in the form of lectures, debates and practical activities, were fundamental to provide spaces for dialogue. In the municipality in question, there is a predominance of latifundio directed to livestock and monocultures, which implied a social structure strongly based on patriarchy and, thus, with ramifications in social, political, imaginary and representational organizations. Therefore, the goal of dialogue and deconstruction of imaginary gender and sexuality, besides being a challenge, is an emerging need. Thus, this paper examines the spatial and historical context of the municipality; develops a conceptual discussion about gender, sexuality, and curriculum. Finally, based on the analysis of the activities developed, reflections on the teaching identity and pedagogical practices are presented. Gender, sexuality and education are complex issues and in constant dispute. Thus, the reflections presented here are part of the political and social struggle for the constitution of societies that learn from differences and diversities.
\end{abstract}

Keywords: Basic Education; Gender; Patriarchate; Sexuality; São Borja / RS.

\title{
1. Introdução
}

A proposta de inserção e diálogo nas escolas a partir da temática do gênero e sexualidade está relacionada a ações de cunho pedagógico, cujo objetivo é a desconstrução simbólica, política e social de estruturas assimétricas e hierárquicas em vigor em sociedades androcêntricas (BOURDIEU, 2002), patriarcais (BIDASECA, 2011 ) e heteronormativas (LOURO, 2000 b). Uma educação voltada para a formação cidadã é consonante com a valorização e problematização das diferenças (SILVA,2015 ).

Embora as temáticas de gênero e sexualidade estejam previstas nos Parâmetros Curriculares Nacionais - Temas transversais (1998) e nas Diretrizes Curriculares Nacionais 
(2013), ainda permanecem como temas polêmicos e como objetos em disputa. Historicamente foram dissociadas do ambiente escolar ( LOURO, $2000 \mathrm{~b}$ ), restritas ao privado, como as sexualidades, ou naturalizados, como as assimetrias de gênero. Todavia, são chaves de interpretação da sociedade e a dissociação dos temas como pertinentes ao debate escolar, aos corpos escolares e ao currículo é uma forma de manutenção das assimetrias de poder que subjugam e violam as sexualidades não hegemônicas (SILVA, 2015) e as diferenças de gênero.

As assimetrias e violências associadas às diferenças de gênero e sexualidade são históricas e estruturais: estão contidas na divisão do trabalho, na construção simbólica (BOURDIEU, 1989) das diferenças. Como consequência, repercutem nos indicadores de violência contra mulheres, homofóbicas e transfóbicas.

Conforme Waiselfisz observa no Mapa de Violência 2015: Homicídio de Mulheres no Brasil, os dados expostos no documento revelam que o país se destaca como um dos primeiros colocados no ranking de feminicídeo do mundo. Atualmente, ocupa o quinto lugar na lista de países mais violentos contra o gênero feminino e o primeiro em crimes de lgbtfobia. Waiselfisz salienta a mudança social que vem ocorrendo no Brasil, quando diz que "[...] essa eclosão, quantitativa e qualitativa, dos indicadores e abordagens acontece de forma paralela a uma reconceitualização de nosso entendimento da violência, pela ampliação de seus significados." (WAISELFISZ, 2015. p. 71). Não apenas a violência física e homicídios passaram alvos de discussão e normativas jurídicas, mas houve também uma mudança no conceito, o que possibilitou identificar com mais propriedade os variados perfis das vítimas.

Embora essas assimetrias, hierarquias e violências sejam onipresentes, cabe ressaltar que nos países do Sul das linhas abismais (SANTOS, 2010), são acirradas pela duradora e particular estrutura patriarcal decorrente dos processos de colonização. Sendo assim, faz-se necessário, tanto por suas especificidades, quanto pelo embate político, favorecer a emergência de múltiplos discursos (ainda predomina o androcêntrico/heteronormativo), assim como, a análise e ações de promoção da cidadania, nesse contexto particular em que está o município de São Borja.

O Município de São Borja ${ }^{5}$ é comumente associado a figuras masculinas da política nacional, como sua referência à "cidade dos presidentes". Cabe destacar, também, sua origem como um dos "primeiros dos Sete Povos Missioneiros", o que remete para o colonialismo, aspecto pouco explorado nessa referência. É um município de fronteira, em que a

\footnotetext{
${ }^{5}$ Município de fronteira com a Argentina, com população de 62.808 ( IBGE, estimativa de 2017), sendo que a população urbana corresponde a 89,74\% (IBGE, 2010).
} 
intencionalidade e presença do Estado na manutenção de seu território se faz pelo estabelecimento de unidades de exército brasileiro. Embora seja uma cidade pequena, sua posição estratégica junto às margens do rio Uruguai sempre lhe conferiu um grande significado na construção da ocupação/colonização do Rio Grande do Sul. Esses elementos reforçam sua constituição androcêntrica ${ }^{6}$. Aqui tem-se uma historiografia e geografia com predomínio discursivo e político dissociado dos múltiplos grupos sociais que compõem o local e assentado no gênero masculino.

Como observa Ribeiro, "A condição de fronteira do Brasil sulino, fazendo concentrar ali a maior parte das tropas do país, por uma parte deu continuidade e função ao antigo ímpeto combativo do gaúcho das correrias". (RIBEIRO, 1995. p. 412). Seguindo a análise do autor citado, reitera-se a História como a Geografia da região foram palco de inúmeros conflitos, onde a busca pelo poder, seja pelo território ou do ideal político, foi determinante na formação da identidade do povo desse local e na herança fundamentada nas relações patriarcais.

Tem-se, portanto, indícios da construção do imaginário do gaúcho (homem) viril e coadunado à paisagem e território (nesse caso, fronteira e bioma Pampa). É uma historiografia assentada na figura e proezas masculinas e heteronormativas. Logo, faz-se necessário tornar objeto de problematização e compreensão da sociedade a construção desses imaginários e papéis sociais. Objetiva-se a desconstrução de assimetrias e emergência das vozes, dos corpos, das sexualidades e das identidades silenciadas e/ou negadas. É nesse campo político, social e identitário que se estabelecem as ações nas escolas locais, a partir do projeto de extensão "Construções e desconstruções do gênero e sexualidade no currículo: tecendo perspectivas para uma educação multicultural", realizado pela Universidade Federal do Pampa - (UNIPAMPA), campus São Borja. O objeto do projeto consiste no diálogo e formação de docentes da rede básica de educação para as questões de gênero e sexualidade. Logo, envolveu as teorias do currículo, gênero e sexualidade.

Dessa forma, as reflexões que seguem são produtos de discussão e revisão bibliográfica sobre a constituição geográfica e histórica do município e atividades realizadas

\footnotetext{
6 Algumas generalizações podem pecar por obscurecer ainda mais a luta de sujeitos tidos como objeto da dominação patriarcal e heteronormativa. Nesse aspecto, cabe ressaltar a resistência dos povos originários, as vozes que a historiografia silencia, o que pode ser remetido, a título de exemplo, aos vestígios históricos e simbólicos de Maria do Carmo, mulher dissonante de sua época que teria sido vítima de feminicídio e, por fim, grupos sócio-identitários de São Borja que atuam fortemente na luta política e social pelo respeito e reconhecimento das diferenças, a exemplo, a ONG Girassol.
} 
com docentes da rede básica de educação. Tem-se, portanto, reflexões iniciais sobre gênero, currículo e sexualidades.

\section{Currículo, Gênero e Sexualidade}

As teorias do currículo demonstram que sua construção pode promover uma educação crítica ou o fortalecimento de processos de dominação. O currículo pode ser um instrumento de superação ou de reprodução das relações de poder, marcadamente patriarcais, racistas e heteronormativas. Todavia, o currículo é, também, um campo em disputa, no qual vem emergindo perspectivas multiculturais (SILVA, 2015). Assim, evidencia-se a urgência de intensificar na problematização cotidiana da escola os temas de gênero e sexualidade, os quais, de acordo com Louro (2000 (a)), tem a centralidade frequentemente dissimulada ou negada. Todavia, corresponde a um campo do conhecimento (SEFFNER, 2014), ao cotidiano dos cidadãos, apresentando-se ou ocultando-se em corpos, discursos e símbolos. Paraíso (2010, p. 588) a partir da diferença, define o currículo como:

[...] território povoado por buscas de ordenamentos (de pessoas e espaços), de organizações (de disciplinas e campos), de sequenciações (de conteúdos e níveis de aprendizagens), de estruturações (de tempos e pré-requisitos), de enquadramentos (de pessoas e horários), de divisões (de tempo, espaço, áreas, conteúdos, disciplinas, aprendizagens, tipos, espécies...). Isso tudo porque o que está em jogo em um currículo é a constituição de modos de vida, a tal ponto que a vida de muitas pessoas depende do currículo.

Dessa forma, corrobora com um posicionamento educacional que problematiza o currículo como um campo de poder. É objeto da manutenção das relações (privilégios) do poder. Tem-se, portanto, o controle sobre as formas de ver o mundo e (re)produzir a sociedade. Assim, o currículo é um campo político e epistemológico em disputa. Logo, tem-se a emergência de outras concepções, como o multiculturalismo (SILVA, 2015), a diferença (PARAÍSO, 2010). A construção do currículo que privilegie a emergência de múltiplas vozes, grupos sociais e ideológicos favorece a emergência da diversidade. Torna-se salutar promover a escola como um espaço de enunciação de múltiplas identidades (HALL, 2001) e o currículo faz parte desse processo.

Conforme Silva (2015), um currículo multiculturalista radicaliza a questão do que deve ser ensinado, evidenciando com isso sua característica de contínua construção, a qual reflete e produz a norma e o desvio, sendo que a igualdade depende de importantes transformações políticas, entre elas as curriculares. A densa reflexão e promoção de ações que favoreçam a emergência em condições de igualdade das identidades de gênero e sexuais favorecem a promoção de direitos humanos e a formação cidadã. Uma educação a partir da 
premissa do multiculturalismo crítico (SILVA, 2015) atua na produção de relações mais harmônicas entre os sujeitos escolares, conformando espaços de enunciações indenitárias em condições de igualdade.

Compreende-se que sexo se refere ao sexo biológico, ou seja, macho e fêmea. Está ligado à genitália que o indivíduo nasce: pênis ou vagina. Já a sexualidade é a forma que o sujeito desenvolve seus desejos sexuais e afetivos. As formas de expressão da sexualidade mais conhecidas são: heterossexual - possui desejo sexual e afetivo por pessoas do gênero oposto; homossexual - possui desejo sexual e afetivo por pessoas do mesmo gênero; bissexual - possui desejo sexual e afetivo por pessoas de ambos os gêneros.

O conceito de Gênero emergiu da necessidade de realizar uma distinção entre as características biológicas dos sujeitos e demonstrar que as masculinidades e feminilidades são construídas socialmente e diferem ao longo do tempo e de sociedade para sociedade. Louro pondera que,

É necessário demonstrar que não são propriamente as características sexuais, mas é a forma como essas características são representadas ou valorizadas, aquilo que se diz ou pensa sobre elas que vai construir, efetivamente, o que é feminino ou masculino em uma dada sociedade e em um dado momento histórico. (LOURO, 2014, p. 25)

Ela ainda destaca que a utilização do conceito de Gênero assume a característica de "uma ferramenta analítica que é, ao mesmo tempo, uma ferramenta política" (2014, p. 25) na busca de uma equidade de gênero e da permissão dos sujeitos vivenciarem suas diversas masculinidades e feminilidades.

\subsection{Gênero, Sexualidade e Identidade Docente}

No decorrer dos encontros realizados ${ }^{7}$ com docentes da Educação Básica ${ }^{8}$, foi percebido a presença massiva de mulheres como profissionais do ensino. A associação da docência a mulheres está envolta no imaginário de que o fazer pedagógico é imanente a elas em decorrência de sua "natureza" e associação à maternidade, desvinculando a profíssão de seu caráter técnico, político e social. Tem-se, portanto, a questão de gênero no cerne da identidade profissional.

\footnotetext{
${ }^{7}$ As atividades realizadas consistiram de uma dinâmica inicial de apresentação. Na sequência a realização de uma atividade com uma caixa na qual alguns(mas) participante deveria retirar um papel que continha uma situação do cotidiano envolvendo gênero e sexualidade. Na sequência, era realizada um diálogo a partir da legislação, temas transversais, conceitos de gênero e sexualidade e metodologias de ensino. Toda a atividade era realizada de forma dialogada. Participaram duas professoras da Unipampa, duas acadêmicas e um acadêmico.

${ }^{8}$ Além dos encontros com docentes, foram também realizados encontros com alunas(os) das escolas. Embora não estivesse na previsão inicial, esses encontros foram demandados pelas escolas. Também cabe destacar que foi um ano tenso na rede escolar em virtude dos atrasos salariais e greves que ocorreram em 2017. Esses encontros também com alunos vinham complementar atividades de docentes ou fomentar o debate.
} 
Esse aspecto já foi salientado por Louro em seus estudos sobre a mulher e o magistério no século XIX. Ao que a autora citada se refere que nessa época, surgiu a construção social que delegava à mulher a função de docente, não pelos seus potenciais intelectuais, mas sim, por sua "natureza materna", como cita em análise do comportamento no fim do século XIX e início do século XX,

As mulheres tinham "por natureza", uma inclinação para o trato com as crianças, que elas eram as primeiras e "naturais educadoras", por tanto nada mais adequado do que lhes confiar a educação escolar dos pequenos. (LOURO, 2012, p. 450)

Nesse trecho é possível identificar a égide patriarcal de colocar a mulher, a profissional, dentro do modelo ideal de sociedade. Se essa mulher, optasse por sair do recôndito do lar para ir trabalhar, deveria exercer uma profissão que a mantivesse no status quo definido para época.

Corroborando com isso, a historiografia até pouco tempo também conferia à mulher um lugar adequado até mesmo na História, contanto (e as vezes omitindo), a existência de diversos perfis da mulher brasileira, padrões comportamentais e socioeconômicos, como se refere Fonseca,

A norma oficial ditava que a mulher devia ser resguardada em casa, se ocupando dos afazeres domésticos, enquanto que os homens asseguravam o sustento da família trabalhando no espaço da rua. Longe de retratar a realidade, tratava-se de um estereótipo calcado nos valores da elite colonial, e muitas vezes espelhado nos relatos de viajantes europeus, que serviam como instrumento ideológico para marcar a distinção entre as burguesas e as pobres. Basta aproximar-se da realidade de outrora para constatar que as mulheres pobres sempre trabalharam fora de casa. (FONSECA, 2012. p. 517)

É devido a essas análises, que as diversas formas como a mulher vem conquistando o seu espaço de direito na sociedade é um, entre muitos fatores, que fazem com que História reescreva o papel das mulheres no/do Brasil. Dessa vez, por elas próprias e não mais apenas por historiadores do gênero masculino, que carregam consigo também uma formação construída socialmente dos perfis de como ser homem e mulher.

Com isso, é possível identificar as relações de poder que permeiam o universo social desde muito tempo. Como na educação, Louro ainda nos remete a pensar "[...] que a história das mulheres nas salas de aula é constituída e constituinte de relações de poder" (LOURO, 2012, p. 478), próprias de uma sociedade que guarda heranças pós-colonialista, como a brasileira.

É notório, no entanto, que a profissão de normalista era exercida, muitas das vezes, por mulheres com classe social privilegiada. Essas jovens que buscavam a profissão enfrentavam 
os seus estudos, como os padres adotam o celibato. Pois, seguindo a análise de Louro, a professora em momento algum deveria ser vista como uma mulher que transmite a sua sexualidade. Não obstante, observa-se que, através da luta de teóricas(os) e movimentos sociais, tem-se de forma paulatina e em meio a conflitos e disputas, a inserção do tema enquanto aspecto pedagógico e social no contexto escolar.

As (os) docentes que participaram das atividades eram heterogêneas(os) entre si. Algumas (uns) haviam iniciado recentemente à docência (aproximadamente entre dois e três anos), outras (os) estavam próximas (os) da aposentadoria. Durante as atividades e diálogos realizados nas escolas, a presença de professores homens foi reduzida. Desses, apenas um professor ressaltou a importância de trabalhar as questões de gênero dentro do espaço escolar, os outros se mantiveram silenciosos durante o debate. Seria temerário tecer suposições sobre esse silenciamento, todavia, pode-se inferir que o tema gênero e sexualidade persiste obscurecido. Não se objetiva a substituição dos espaços de poder de um gênero por outro, mas que todos, assim como sujeitos associados às sexualidades não hegemônicas, ocupem esses espaços de forma igualitária.

Gênero e sexualidade são temas a serem abordados por todas (os) os profissionais. As diretrizes da Base Nacional Comum Curricular afirmam ser necessário, "Refletir sobre as experiências corporais pessoais e coletivas desenvolvidas em aula ou vivenciadas em outros contextos, de modo a problematizar questões de gênero, corpo e sexualidade." (BRASIL, 2016, p. 165). Assim, o silêncio, a influência de religiões e a confusão acerca dos temas contribui para que os mesmos sejam evitados nos processos pedagógicos. Todavia, reforça-se sua presença em corpos, contextos e cotidianos de todas(os) os sujeitos do espaço escolar.

É salutar destacar o importante papel de professoras dentro desses espaços, uma vez que vivenciam as opressões e discursos que subjugam as mulheres. Todavia, observou-se nas atividades que muitas delas apresentem confusão ou desconhecimento sobre as concepções de gênero e sexualidade e sua inserção no currículo. Ao mesmo tempo, os espaços de formação e diálogo tornaram-se um espaço de "desabafo", pois são temas presentes na vida particular, nas sexualidades não hegemônicas de filhos(as), nos contextos de divórcio, etc. Assim, embora a proposta inicial consistisse em debater os temas transversais e propor metodologias, foi preciso explorar os conceitos e complexidades em que os temas de gênero e sexualidade manifestam-se. 
Esses aspectos elencados demonstram que o ambiente escolar encontra-se em estados diferentes de desconstrução. Ao mesmo tempo em que foi identificado profissionais que inclusive fizeram pesquisa de campo com alunas(os) da rede básica para compreender a questão do nome social, evidenciando práticas pedagógicas a serem aprendidas também pela academia, observou-se o acirramento do debate que busca restringir as temáticas aos componentes de ciências, o que potencializa a dissociação desses temas de seus conteúdos sociais e políticos.

Gênero e sexualidade são temas, objetos de problematização da sociedade contemporânea, mas também, estão nos corpos e cotidianos de professoras (es), alunas (os). São elementos que compõem a identidade docente, tanto no âmbito escolar, quanto na vida privada e pública. Entre muros e fora dos muros da escola, as desconstruções dos processos de dominação e violência associados ao gênero e sexualidade são imprescindíveis.

\subsection{Construções e Desconstruções: o projeto e o seu trabalho}

Com os fatores já citados no decorrer deste texto, isto é, a herança patriarcal na cidade de São Borja e a mulher/professora nas escolas de ontem e de hoje, pode-se compreender uma parcela de como foi adentrar os "muros" escolares para discutir sobre gênero e a sexualidade na sociedade analisada.Embora o ambiente escolar, mesmo com todas as diretrizes evocadas pela Lei de Diretrizes e Bases (LDB), os Parâmetros Curriculares Nacionais (PCNs) e a Base Nacional Comum Curricular (BNCC), ainda demonstram dificuldade em abordar o gênero e a sexualidade como formas de interpretar a sociedade e as estruturas sociais e de poder. Persiste como um tema tido como "tabu".

É devido a isso, que a intenção inicial era trabalhar o currículo, entendido como campo de disputa, de poder e de tensão entre os diversos grupos sociais. A partir daí, alongar-se-ia para a comunidade escolar, compreendendo a função de criar pontes entre a Educação Básica e a Universidade.

Entretanto, como já mencionado e problematizado por Silva, o currículo é "[...] um aparelho ideológico do Estado capitalista. O currículo transmite a ideologia dominante. $\mathrm{O}$ currículo é, em suma, um território político". (SILVA, 2015, 148). Existem nesse campo de disputa, mecanismos para adiar ou amenizar as possibilidades de se discutir formas de inserção de temas considerados pelo público conservador como desnecessários e/ou polêmicos. Com isso, os conhecidos e conservados "tabus" permanecem como entraves à constituição de espaços multiculturais na prática, na política e, de forma epistemológica. 
As temáticas que envolvem gênero e sexualidade dentro da escola são impossíveis de serem negadas, abafadas ou não problematizadas, como cita o Parâmetros Curriculares Nacionais em,

A sexualidade no espaço escolar não se inscreve apenas em portas de banheiros, muros e paredes. Ela "invade" a escola por meio das atitudes dos alunos em sala de aula e da convivência social entre eles. Por vezes a escola realiza o pedido, impossível de ser atendido, de que os alunos deixem sua sexualidade fora dela. (BRASIL, 1998, p.292)

Nisso, o projeto foi desenvolvendo para cada escola uma atividade especial, seguindo sempre um roteiro que incluía um arcabouço teórico e prático. Foram debates e dinâmicas, que trouxeram para o centro das discussões fatos que muitas vezes, são relegados a segundo plano nas escolas.

As dinâmicas foram pensadas para abrir os debates, ou seja, em muitos momentos uma simples afirmação à exemplo do que foi utilizado, cita-se, — "Durante a aula de educação física o baixo desempenho de Luciano foi definido pelo professor com a seguinte afirmação: "Você está correndo como uma menininha" — acaba servindo de estopim para por em discussões aspectos que podem ocorrer no ambiente escolar. E que muitas vezes, são tratados como comportamentos normais por parte de professoras/es e de alunas/os.

Os relatos das aproximações das questões de gênero e sexualidade predominaram no cotidiano escolar das relações sociais, uma vez que emergem em corpos, discursos e conflitos entre alunas (os). Foi pouco relatada a abordagem nas práticas de ensino. Também não foi possível identificar, conforme coloca Silva (2015), a abordagem da temática como uma chave de interpretação da sociedade, sendo comumente remetido a luta de "minorias". São necessárias abordagens que promovam a temática em sua relação com a estrutura social, hierarquias e relações de poder.

Esses momentos, deslocaram algumas/ns professoras/es da sua zona de conforto em direção ao debate construtivo. O uso de exemplos que podem ocorrer no cotidiano escolar, a emergência dos exemplos e situações narrados sobre alunas (os), o diálogo sobre noções de gênero, sexualidade e escola estiveram imbricados com aspectos próprios da cultura fronteiriça, tornando a compreensão da temática mas propícia ao debate, o que oportunizou fundamento e diminuição da distância entre teoria e a prática. As atividades demonstraram a urgência em fomentar esses espaços de diálogo, de troca de saberes e de construção de outros saberes.

Acredita-se no grande potencial do projeto em fomentar instabilidades nessa sociedade pós-colonialista, fundada no patriarcado e contribuir para a constituição de uma sociedade que 
viva a diferença e o respeito a partir da educação. Todavia, o percurso é longo, contínuo, político, pedagógico e social.

\section{Conclusões}

As atividades realizadas mostraram a importância da produção compartilhada de saberes plurais entre acadêmicas(os), docentes do ensino superior e do ensino básico. A universidade tem muito a contribuir com o ensino básico e muito a aprender com esse. Temse, portanto, uma frutífera articulação entre a esfera do teórico e da prática. Torna-se um objetivo corroborar na formação cidadã crítica, na qual se tenha enfoque na compreensão das diferenças como inerentes à sociedade, assim como reconheça a estrutura histórica, social, patriarcal, racista e heteronormativa nos discursos, estruturas e contextos escolares.

É possível inferir que, em virtude da luta social e política, tem-se a inserção nessa "arena" de vozes dissonantes de grupos até então hegemônicos nas posições de definir e estabelecer perspectivas curriculares. Todavia, o debate e busca por instrumentos e compreensões, ou seja, ações na formação continuada de docentes da rede básica, são imprescindíveis para o êxito nesse objetivo. Nesse sentido, é necessário refletir e propor formas de diálogo com esses profissionais e criar coletivamente instrumentos e estratégias para a educação básica.

As questões de gênero e sexualidade são atravessadores de todas(os) sujeitos escolares e a omissão e naturalização que no passado fizeram-se presentes, hoje não são mais possíveis. E essa emergência não é um "problema", mas uma oportunidade para repensar as estruturas sociais, trabalhistas, de direito, etc. E é como possibilidade de ler e reconstruir solidariamente o mundo que esses temas emergem no currículo.

\section{Referências}

BIDASECA, Karina. Mujeres blancas buscando salvar a mujeres color café: desigualdad, colonialismo jurídico y feminismo postcolonial. Andamios. Revista de Investigación Social. Vol. 8, Num. 17, septiembre-deciembre, 2011, p. 61-89.

BOURDIEU, Pierre. A dominação masculina. 2 ed. Rio de Janeiro: Bertrand Brasil, 2002 O poder simbólico. Rio de Janeiro: Bertrand Brasil, 1989. 
BRASIL. Ministério da Educação. Secretaria de Educação Fundamental. Orientação Sexual. In. Parâmetros Curriculares Nacionais:terceiro e quarto ciclos: apresentação dos temas transversais.Brasília: MEC/SEF, 1998.

BRASIL. Ministério da Educação. Secretaria de Educação Fundamental. Orientação Sexual. In. .Base Nacional Comum Curricular. Brasília: MEC, 2016.

FONSECA, Cláudia. Ser mulher, mãe e pobre. In. DEL PRIORE, Mary (org.). História das mulheres no Brasil. 10 ed. São Paulo: Contexto, 2012. p. 510 - 553.

LOURO, Guacira Lopes. Currículo, Gênero e Sexualidade. Porto: Porto Editora, 2000 (a).

Mulheres na sala de aula. In. DEL PRIORE, Mary (org.) História das mulheres no Brasil. 10 ed. São Paulo: Contexto, 2012 . p 443 - 482.

Pedagogias da sexualidade. In. LOURO, Guacira Lopes et.al. O corpo educado. Belo Horizonte: Autêntica, 2000 (b).

Gênero, sexualidade e educação: uma perspectiva pós-estruturalista. 16 ed.

Petropólis, RJ: Vozes, 2014.

PARAÍSO, Marlucy Alves. Diferença no currículo. Cadernos de Pesquisa. Vol. 40, num. 140, maio/ago. 2010, p. 587-604.

RIBEIRO, Darcy. Brasis Sulinos.In. O povo brasileiro: formação e o sentido do Brasil. São Paulo: 1995. p. 408 - 447.

SANTOS, Boaventura de Sousa. Descolonizar el saber, reinventar el poder. Montevidéu: EdicionnesTrilce, 2010.

SILVA, Tomaz Tadeu. Documentos de Identidade: uma introdução às teorias do currículo. 3 ed. Belo Horizonte: Autêntica Editora, 2015.

Waiselfisz, Julio Jacobo. Mapa da Violência 2015: Homicídio de Mulheres no Brasil. Brasília DF. 2015. Disponível em: $\leq$

www.mapadaviolencia.org.br/pdf2015/MapaViolencia_2015_mulheres.pdf >. Acesso em: 16 . jan. 2018 